Article

\title{
Open Science in the Humanities, or: Open Humanities?
}

\author{
Marcel Knöchelmann $\mathbb{D}$ \\ Department of Information Studies, University College London, Foster Court, Gower Street, London WC1E 6BT, \\ UK; marcel.knochelmann.15@ucl.ac.uk
}

Received: 9 October 2019; Accepted: 13 November 2019; Published: 19 November 2019

\begin{abstract}
Open science refers to both the practices and norms of more open and transparent communication and research in scientific disciplines and the discourse on these practices and norms. There is no such discourse dedicated to the humanities. Though the humanities appear to be less coherent as a cluster of scholarship than the sciences are, they do share unique characteristics which lead to distinct scholarly communication and research practices. A discourse on making these practices more open and transparent needs to take account of these characteristics. The prevalent scientific perspective in the discourse on more open practices does not do so, which confirms that the discourse's name, open science, indeed excludes the humanities so that talking about open science in the humanities is incoherent. In this paper, I argue that there needs to be a dedicated discourse for more open research and communication practices in the humanities, one that integrates several elements currently fragmented into smaller, unconnected discourses (such as on open access, preprints, or peer review). I discuss three essential elements of open science-preprints, open peer review practices, and liberal open licences-in the realm of the humanities to demonstrate why a dedicated open humanities discourse is required.
\end{abstract}

Keywords: open humanities; open science; digital humanities; scholarly communication; peer review

\section{Introduction}

There is a long history of sorting disciplines into clusters, primarily the sciences and humanities [1-3]. These clusters are, at times, extended to a triad with the social sciences in between. Contrary to the impression this clustering conjures, though, no exact distinction can be drawn between the sciences and the humanities (or the social sciences in between). Not one binary opposition, nor a combination of several ones, can describe the differences that would suffice for a clear-cut separation of disciplines: understanding or explaining, idiographic or nomothetic, qualitative or quantitative, meaning or theory-all fall short of describing but a few temporal or field-specific regularities. Any such distinction can at best approximate what unites and separates disciplines so that, in the end, it is a question of purpose or necessity on the basis of which the exercise of unifying or separating disciplines is to be undertaken. One such necessity arises when norms and practices of open and transparent research and communication are to be debated. Disciplines share characteristics of research and communication practices that require a discourse on these practices to sort disciplines into clusters so as to sufficiently address the characteristics of these disciplines.

There is a specific discourse dedicated to open practices for disciplines of the sciences: open science. This discourse regularly takes for granted to speak for scholarly communication as a whole. However, already its name-open science-indicates that this discourse is not concerned with the humanities but with a cluster of scientific disciplines. There is no such discourse dedicated to the humanities. This is the case, although research and communication practices in disciplines commonly clustered into the humanities do share characteristics, that could—and, I argue, need to-be addressed by a 
coherent discourse as well. The coherence of this discourse builds upon the unifying characteristics of its disciplines. Without such unifying grounding, contributions to a potential discourse would only be concerned with elements of some disciplines-in the humanities, for instance: philology, philosophy, history, theology, among others-instead of the humanities as a whole. The result would be a fragmentation into several smaller discourses such as open philology, open philosophy, etc.

Characteristics on the basis of which disciplines can be sorted into the humanities are, for instance, an emphasis on perspectivity (as opposed to objectivity in the sciences), verbality (as opposed to reliance on models), or historicity (as opposed to systemic integration) of contributions to discourses in these disciplines [4]. These characteristics are expressive of the research paradigms and epistemologies employed in what is commonly termed the humanities: the importance of hermeneutics, source criticism, and nuanced, contextual meaning [5-7]. These more abstract characteristics lead to distinct practices such as the reliance on long-form publications (primarily the monograph), qualitative arguments, slower, editorially-heavy publishing processes, recursivity of its discourses, critique, and qualitative embedding of references [8-10]. ${ }^{1}$ Moreover, the humanities live on a culture of debate, with the analysis and dialectic of interpretative understanding at its core [11]. Scholars in the humanities focus on "interpretation and critical evaluation, primarily in terms of the individual response and with an ineliminable element of subjectivity" [12] (p. 23). The resulting discourses are based on the power of arguments so that the "overall cogency of a substantial piece of work seems more closely bound up with the individual voice of its author" [13] (p. 75). Dissonance is essential and there is no need for agreement in a discourse for it to be successful in scholarship. Scholars may never reach consensus; their arguments of disagreement are essential bits of knowledge production.

All this makes critiquing and reinterpreting existing contributions to a discourse-thus, continually and recursively coming back to previous work-an integral part of the humanities. A prerequisite for this is that scholarly communication practices enable such a culture of debate to flourish. A liberal understanding of scholarly practices enabled by free access to contributions, diversity of argument, intention of the author to contribute to discourses-as opposed to the intention to publish for the sake of authorship and reputation-can be supportive of such flourishing (as is discussed for the characteristics of the sciences in open science). There is, however, no discourse concerned with such elements that are dedicated to the here-offered characteristics of the humanities. In other words: though there is no one field of scholarly communication — but at least one for each cluster of scholarship-there is currently only one dedicated discourse on open research and scholarship, and this is open science.

\section{Open Science, Open Humanities, and Digital Humanities}

\subsection{The Meaning of Discourse}

There is a long and strong thread of - mostly scholarly-discourses on topics of openness in all forms: open source, open access, and open science in particular, and the digital means and discourse conventions enabling openness of scholarly communication in general. Moreover, discourse is a term with a difficult genealogy. Its meaning varies depending on the disciplinary and temporally-situated context. This necessitates differentiating what I imply to with my claim for a dedicated discourse.

Discourse here refers to a debate that includes various forms of textual or oral communication as contributions to a specific enquiry and body of knowledge. Such discourse is both the intellectual construction of the object of enquiry and serves as a reference to the practices it is dedicated to (in discursive form). This notion does not refer to a Foucauldian conception of discourse that includes practices, but comes closer to the early Habermasian tradition that posits as discourses a rational exchange of communicative action. The closest the conception of discourse in this article comes to is

1 There are variances in these, of course. As mentioned in paragraph one, such unifications are approximations at best and so it needs to be stated that, for philosophy, for instance, the monograph has become less important. 
that offered by Hyland [8]. It is the engagement of experts—or novices who aspire to become experts by contributing to discourses-in communication that is governed by conventions fixed temporally only by the very members of that discourse. Contributions to a discourse are accepted and negotiated by those who already partake in the discourse. On the one hand, this is based on peer review or editorial decision making, and, on the other hand, on less standardised forms of communication, for instance, in blogs, at conferences, or on social media.

The discourse, therefore, is constituted by the contributions to it which are either accepted formally through selection, or included informally through references to them. Crucially, such notion of discourse links the communicative action happening within the discourse to the individuals who contributed to it. They form discourse communities and, as Hyland summarises, the ways the members of these communities "understand knowledge, what they take to be true, and how they believe such truths are arrived at, are all instantiated in a community's discourse conventions" [8] (p. 5).

A new discourse is rarely established by an artificial gathering of contributions, but is formed organically by the need of enquiry or the lack of a coherent body of knowledge. Hence, proposing a discourse means demanding more enquiry to form a more coherent body of knowledge. Contributions to a later-formed discourse may already exist in disparate forms. As I will show in Sections 2.2-2.4, there are few instances where the object in question-open practices in the humanities—is already touched on. These instances are not linked, though, because of the lack of the dedicated discursive realm. Similarly, the discourse on open science was not opened as a discursive realm dedicated to open science. Its origins are widely spread and contributions to it may stem from a wide array of other discourses that existed before open science was established (see Section 2.2 for a discussion of open science). It is, thus, not merely the dedication of a new terminology. The term open humanities has been used before, but this does not mean that there is an open humanities discourse. Demanding such a discourse does not dismiss existing explorations of open practices in humanities disciplines, but calls for a dedicated communicative realm where such enquiries have space to be taken on in an integrated and focussed manner.

Moreover, the members of a discourse community may have worked on practical implementations, thus, conversions of knowledge into practices or experimentation to induce practical knowledge. That these practices are concerned with the knowledge in action that may be part of a discourse does not constitute that these practices are themselves components of that discourse. Only by means of textual reporting do the experiences of implementing practices or applying knowledge feed back into discourses, especially discourses governed by scholarship such as open science, digital humanities, or a potential open humanities. This distinction is essential to the ensuing discussion in this article. Though there are or have been instantiations of practices in a form of open humanities-irrespective of these being called open humanities-these instantiations do not as such contribute to an open humanities discourse; they either form minor contributions to the digital humanities discourse (see Section 2.4), or they contribute to other, disparate discourses which are not linked to each other (as in the case of some of the elements such as preprints or liberal licensing discussed in Section 3). Already the existence of such practices that are linked to each other through their integrated nature in the field requires that the enquiries into these practices, their textual representations, and the knowledge of these practices are linked as well.

Thus, what a discourse is cannot be defined before its existence, as only the content of those elements of communication that contribute to the discourse determine its boundaries. With this in mind, I do not aim to define what open humanities needs to be in general or in detail, but demand that there is a discursive realm where potential elements have the potential to be linked and debated. These elements will then render the realm and define its boundaries. Open practices in the humanities could be an element of either open science or digital humanities discourses. There is no definition or guard preventing the uptake of this direction within the existing discourses. However, as I will demonstrate with the relevant literature in Section 2, and the discussion in Section 3, existing contributions to 
these discourses show that they are conceptionally unqualified (open science), or lack coherence and dedication (digital humanities).

\subsection{Open Science}

The term open science refers to the historical and contemporary practices and norms of open research and communication in disciplines of the sciences as well as to the discourse on these practices and norms.

David [14] finds historical origins of open science practices in early developments of the then still less formal conduct of natural philosophical enquiry in the late sixteenth century-a time when there was not even a separation of clusters of scholarship into sciences and humanities. Vicente-Saez and Martinez-Fuentes [15] aim to determine an integrated definition for the proclaimed "disruptive phenomenon" that open science is and arrive at: "[o]pen [s]cience is transparent and accessible knowledge that is shared and developed through collaborative networks". In addition to having a primarily static definition of open science, they remain diffuse on what knowledge is. Madsen simply sees open science as a movement that "seeks to promote openness, integrity and reproducibility in [scientific] research" [16]. Fecher and Friesike [17] have a more wide-ranging approach to defining open science, including processes, infrastructures, measurement, and society outside institutionalised academia. Though they state in their introduction that open science is concerned with the "future of knowledge creation and dissemination", making no distinction here between clusters of disciplines, they only refer to scientists (next to politicians, citizens, or platform providers) when they discuss their open science schools of thought. They either presume that, due to epistemological distinctions, the humanities disciplines are not to be found in the realm of knowledge production, or they locate the humanities disciplines outside of any of their five schools of thought of open science. Such scientific perspective is further reinforced by Friesike et al. in another study on the emergent field of research on contemporary openness in research [18]. A different approach to defining open science comes from a review conducted by Peters [19]. After having reviewed the dimension and some historical origins of thought about open science, Peters offers conclusive remarks about the nature of thought that underscores open science and the broader philosophy of openness. What he does not do, though, is examine the application of this in specific research, thus, potentially enlightening the eventual differences of the development of an open culture between disciplines of the humanities and the sciences. Similar approaches and shortcomings can be found in other articles concerned with open science (see [20] or [21]).

Thus, it can be confirmed that open science is taken to be literal-science-related. Open science is a concept for scientific research; the broader terminology encompassing also humanities and social science disciplines may be open scholarship, which, in short, means "opening the process of scholarship", irrespective of discipline [22]. Thus, by definition, open scholarship includes all scholarship-irrespective of disciplinary specifics. But the above-mentioned characteristics of the humanities necessitate such differentiation. And with the humanities being in the process of opening communication and research practices as well, a dedicated space is required for debating these processes and emerging practices-one that complements open science but does not resolve into the overtly abstract open scholarship. Such a dedicated discourse should not be read as a demand to separate sciences and humanities or to reinforce a dichotomous perspective on scholarship, but as a reference to the unifying aspects of disciplines and their practices that allow for such a clustering. Moreover, what this overview of the definitions of open science shows is that it has shortcomings in addressing the humanities. Open science is not simply reducible to scientific disciplines and it is not my objective to do so; however, it is, as the literature shows, the case that open science does not address the unique characteristics of the humanities both terminologically and conceptually, making an open humanities discourse necessary.

\subsection{The Necessity of a Discourse on Open Humanities}

Arguments for the necessity to establish such a dedicated discourse can be made in manifold ways: the humanities are lacking behind the sciences in the transformation towards openness; the humanities 
are but a by-product of open science due to the lacking of an own discourse; the fragmentation of discourses about open practices in the humanities requires an integration of these smaller discourses into a single discourse (for instance, the connection of preprints and peer review as discussed in Section 3); there lies strength in a focussed, single voice of a discourse community such as (a potential) open humanities with which to address issues of policy and funding that are more and more concerned with openness. The most pressing argument, however, comes from within scholarship of the contemporary humanities: the inadequacies of the current practices of scholarly communication require a systemic approach to finding new solutions. Dedicating a discursive realm termed open humanities to this quest not necessarily means that openness is to be taken as the only solution to these shortcomings. But without a discourse analogous to that of open science, there is no realm within which the potential of openness as a solution can be determined for the humanities.

To mention are among the inadequacies of communication practices in contemporary humanities, for instance, the detrimental ways "peer reviewers criticize one another" [23]; the "great many unnecessary and inadequate publications" because of wrong incentives and evaluation mechanisms [13]; the fear of subjectivity that is immanent to judgement of quality alongside the denial of subjectivity in quantitative measurement [24]; the different funding and financial support structures that are unfit for a quicker uptake of open access in the humanities [25]; the debate around the "problem of value, transparency, and distributed financing of disciplinary activities" that arises because of the reluctance of learned societies to engage in more open processes [26]; the poisoned paradigm behind productivity and excellence, because of which scholarly communication is increasingly alienated $[13,24,27,28]$. Some of these issues are equally applicable to all disciplines, but by means of their discourse on openness, these issues are regularly addressed for the sciences (but not so for the humanities). The latest example for this is the recently published Ten Hot Topics around Scholarly Publishing by Tennant et al. [29].

Tennant et al.'s review article provides a useful guide to current debates in scholarly communication in the sciences; it is framed, however, as a review of scholarly publishing as a whole. This framing would make it necessary to include perspectives on the humanities which it obviously lacks. ${ }^{2}$ Of the ten hot topics, only three appear to be not focussed on journal articles and only four are not primarily concerned with scientific literature. Especially those topics that take on issues of research quality, judgement, and objectivity do not discern the profound differences that are in place between the communication practices of scientific and humanities disciplines. This makes both choice of and approach to the disputed topics a perpetuation of debates rooted in scientifically minded open scholarship practices-in short: open science. What, then, are hot topics in (open) humanities publishing?

A point can be made about the higher pressure of openness in scientific disciplines because of more policy work. Indeed, open policy is a key element of open science as outlined in some of the conceptual frameworks such as Foster Open Science. This is less so the case in the humanities. The demand for openness in the humanities seems to be rooted in scholarship itself, whereas it is rooted in both scholarship and policies in the sciences. While this may impact the pace of implementing open practices in the humanities, it does not affect the necessity to have a discourse on these practices.

\subsection{Open Access, Open Humanities, and Digital Humanities}

Open access is one of the hot topics found in both the sciences and the humanities. But as opposed to issues such as peer review, preprints, or licences, open access in the humanities is well-established as a discourse, or: within the discourse on open access, distinctions are made between the sciences and the humanities [30-35]. Though the early uptake of open access took place in non-humanities disciplines, already the early declarations on open access include the humanities, with the Berlin

2 As the authors state in the article, the choice of topics arose by means of a somewhat democratic process through a discussion on social media. The demos in this process, however, may have been unrepresentative for the humanities resulting in these science-focussed ten topics. 
Declaration explicitly being issued as "Berlin Declaration on Open Access to Knowledge in the Sciences and Humanities" [36] (own emphasis). Hence, other than for complementary elements of open science, the humanities developed their own discourse on open access, often focussing on the technicalities of implementing more open forms of publishing. However, whereas open access to scientific literature is embedded in an established discourse on open science, open access to scholarly literature in the humanities often remains in quarantine without a broader discursive framework-such as open humanities-within which it could be embedded. Even Kleineberg and Kaden, who enquire the need of a concept of open humanities, cling to open access as a key issue already in their heading (though they do refer to open research data and open review as well in their article) [37]. Kleineberg and Kaden's contribution shows that, theoretically, there is a discourse on open humanities in place. In practice, however, it seems to be mostly invisible, especially in comparison with open science and digital humanities as well as in reference to the fundamental changes potential open practices in the humanities would mean for scholarship.

The reluctance of an uptake of open humanities may be due to the outsourcing of digitality in the humanities that is unseen in scientific disciplines. Whereas digital methods are integral to the disciplines of the life, natural, or applied sciences, the humanities developed digital humanities to devise new methods empowered by digitality. In other words, where digitality is part of each scientific discipline, open science is the dedicated realm for debating open practices in the sciences; humanities scholars would refer to digital humanities for digitality in humanities disciplines but lack a discourse as a reference to open practices. The digital humanities appear with a twofold mission: applying digitality to support or help answer questions in traditional humanities disciplines, and exploring what it means to be human in an increasingly digital environment [38].

The former mission is transdisciplinary in nature, bridging humanities with digital specialist realms. Because of this nature, though, it advances only what is already enquired in the humanities but may not lead to new epistemological efforts; or, as Gibbs and Owens argue, "[d]espite significant investment in digital humanities tool development, most tools have remained a fringe element in humanities scholarship" [39]. Digitality remains an add-on to the humanities, a set of tools and approaches that requires more focus and aspiration for genuine integration into the traditional disciplines [40].

The latter mission seems philosophical, or even sociological, in nature, touching on questions of digital hermeneutics and ontology. It may well be argued that this is a genuine task for philosophers or sociologists which only appears in the guise of a different discourse, termed digital humanities.

Overall, this layover discipline may have the potential to gather scholars to form a community that drives a discourse on open humanities-only termed digital instead of open humanities. This is questionable, though. Much of the discourses within digital humanities focus on digital practices, applied methods, or projects, instead of on open practices comparable to open science. ${ }^{3}$ There are exemptions to this, authors who directly or indirectly analyse or discuss elements considered to be part of open science (or open humanities respectively); examples include Borgmann, who discusses "publication practices, data, research methods, collaboration, incentives, and learning" for the "future of digital scholarship in the humanities" [41] (p. 5), thus describing essential prerequisites for open humanities. Bianco emphasises the "tremendous opportunities" that digital humanities have "to open up research modes, methods, practices, objects, narratives, locations of expertise, learning and teaching" [42], but fails to connect this to any of the larger contexts of open science/humanities or open scholarship. Borrelli looks at the distinction of digital practices as opposed to digitalised practices [43], touching on open access and peer review. Pritchard looks at an early, concrete version of open scholarly communication in the humanities from which he deduces more general findings about

3 See, for instance, key journals: digital humanities quarterly, Debates in Digital Humanities, Digital Scholarship in the Humanities, ZfdG - Zeitschrift für digitale Geisteswissenschaften, Digital Studies / Le champ numérique, or International Journal of Humanities and Arts Computing. 
pre-/post-prints, open access, and a digital, potentially open infrastructure in classical studies [44]. Kuhn and Hagenhoff analyse requirements of digital monograph publishing and conclude with a decisively progressive, open potential for an outdated publishing model [45]. Fitzpatrick contributes comprehensive discussions of inadequate scholarly communication practices for which openness is offered as the best way forward [46-48]. Cohen discusses digital processes as a possible solution to one of the fundamental problems scholarly communication in the humanities exhibit: the social contract that is actualised by traditional, institutional publishing [49]. Again, this article makes no reference to open humanities (or open science/open scholarship respectively).

These contributions are starting points for debates. But their glaring shortcoming is that they are not integrated into a dedicated discourse, and, instead, remain disintegrated and a minor concern next to the many contributions on methods and projects that appear in the digital humanities discourses. Integration here means bringing together the different ideas and enquiries to debate their interconnectedness and implementation in practice. Combined, the various open practices pose a fundamental change of scholarship in the humanities and to get scholars to engage with the shaping of these practices, there needs to be a single discourse as a reference, one that is centred around open humanities and not mixed up with the various debates on methods presented in the digital humanities.

Conclusively, thus, the digital humanities have a topical agenda that is only to a lesser degree concerned with what would be an open humanities discourse. In the following section, I will look at some of the elements that such a discourse would be required take on and reconfigure.

\section{Discussion of Practices of Open Science and Their Applicability in the Humanities}

The Foster Open Science taxonomy names a variety of elements from open access and open data to open reproducible research and open science policies, tools, or guidelines as first order elements of open science [50]. Most of these elements further spread to second or third order elements among which range some of the often-debated topics such as open metrics and impact or open peer review. This taxonomy comprises of many terms explicitly connected to the sciences. As apparent by the terminology, these elements are largely indifferent to the humanities: they are intended to advance, or improve, scholarship specifically in scientific disciplines by making it more open. I will discuss three key elements of the open science taxonomy with respect to their meaning and how the distinction of practices requires a different understanding of these terms in the humanities.

\subsection{Preprints in the Humanities}

A preprint is a manuscript of an article, book, or chapter that is being published in a distinguished online repository before it is formally published in a journal or as a book [51,52]. This quite general definition can be discussed in more detail with respect to its elements: the manuscript is usually one authored for the purpose of being published in a peer reviewed journal or book; publication online in a repository means that the manuscript is published rather informally-i.e., not necessarily formatted according to a publisher's guidelines-on an online server that functions as a repository for such manuscripts, optionally specifically for a discipline. This online publication is freely accessible with respect to a creative commons licence; the manuscript is likely to be published in a similar, but potentially revised version formally later on. The ostensibly outdated term preprint derives from the idea that the manuscript is available for debate before its formal imprimatur in a journal or book, thus, before it is printed - irrespective of this being done with ink or digitally.

This also enlightens about the purpose of using preprints: it accelerates scholarship without compromising authorship and enables early debates $[53,54]$. The formal publishing process usually takes time, especially because of the standard pre-publication peer review [55]. During the time of this peer review, potential readers can already evaluate and judge the research as it is publicly available as a preprint. At the same time, the author(s) can take advantage of the preprint because they have an early citable and timestamped manuscript for the time of it being in review for a journal or book. 
These characteristics have a potentially positive impact on scientific scholarship, as Tennant et al. [29], Ginsparg [56], or Taubes [57] suggest. What these authors do not touch on is that this may be different in humanities disciplines, where preprints have as yet a much smaller presence than in scientific disciplines. There are far fewer preprint servers for humanities disciplines than there are for scientific disciplines [58], which can be explained with the much smaller output of publications in the humanities, their (sometimes) geographically limited importance, and perhaps the reluctance of humanities scholars to engage in progressive, digital publishing procedures in general.

Kleineberg and Kaden [37] discuss how there is no established culture for preprints in the humanities, though their publication processes are particularly long-termed. Laporte [59] identifies several challenges that arise for humanities scholars to have a more established preprint culture. One of these is that, other than in most discourses in the sciences, those of the humanities are still highly (geographically) regionally rooted and make use of a variety of languages and discursive norms instead of resorting to English as a lingua franca. This goes along with the reach of journals and book publishers who have more individual, language-dependent audiences, which makes it much harder to have a single space for an international discourse. Another challenge is posed by the high share of monographs among the overall output as well as popular articles, which further divides the output of the already considerably smaller amount of humanities publications. Those obstacles may well be overcome by highly specialised or well indexed preprint servers; but apart from the conception in theory, these characteristics are a reason for the difficulty of finding a critical mass for the uptake of active preprinting in the humanities.

Geltner, the founder of a preprint server for medieval studies [60], argues strongly in favour of preprints [61]. One of his key arguments is to encourage more curation by editors actively reaching out to authors of compelling new works to convince them of publishing with their journals. If this new work would have been uploaded to preprint servers, the whole process of active curation would be strengthened, the argument goes. Preprints in the humanities are, for Geltner, not about "“"accelerating research," but rather protecting research as a curiosity-driven endeavor [sic]" [62]. It remains questionable whether such a form of curation is incentive enough for scholars to engage in authorship and preprinting, only then to be targeted by journal acquisition editors with publication advertisements. If such targeting led to publications in more prestigious journals, most authors would be encouraged to take the effort. But it may as well be the rather less prestigious journals that would aim for more targeting - a scenario no discourse or author may wish for (irrespective of the fact that the concept of prestige of journals is highly contested in the first place). Moreover, the purpose of preprints is to enable discussion for the time a manuscript is in review, not before it is submitted to a journal for review.

Another yet undebated point can be made with reference to the nature of discourses particularly in the humanities, and whether scholars in the humanities may be better served with more rapid formal publication, rather than the formal publication remaining the same and instituting preprints as a temporal placeholder: in disciplines of the sciences, especially in those that have a high uptake of preprints such as physics, formal publication is generally conceived to be, literally, the formal last step. At that point in time, the content of the manuscript is generally already known within the discourse community and has gone through debate [63] - just what preprints aim to facilitate. Other scholars had the chance to incorporate and work with the knowledge drawn from the research reported in the preprinted manuscript. The purpose is clear-a sensible procedural step to accelerate scholarship during that time in which the manuscript is in review. The downside is that this step reinforces the impression that both the formality of the publication and its closed review process are required. This impression may be falsely conjured as there may not need to be a closed review process, so that 
preprints would either not be necessary or the preprint would be the final publication itself (making the practice of preprinting redundant). ${ }^{4}$

Another characteristic may be even more imperative as an argument against preprinting in the humanities. It is based on the importance of the historicity of publications. This is different in the sciences, where the most recent version of a publication - if approved of by peer review-is essential: the up to date, reliable, and reproducible research reported in the publication counts, not the historicity and versioning of the publication. This is not the case in the humanities which can be illuminated by an example.

Consider that, by means of peer review, there is a change in the content from preprinted manuscript to final publication, for instance, in the line of argument or references included. This change will have to be reflected in case a future author aims to discuss this publication. This future author may no longer merely write: author A claims that X; she will instead be required to write: author A claims that $X$ and reviewer $R$ adds that $X^{Y}$. If authors in the humanities adopted preprinting, there would always be at least two versions of an article available (provided the article got accepted after revision). This may sound trivial. But for disciplines that emphasise the importance of hermeneutics and source criticism, where editorial history is a key concern, such details require attention.

It is, therefore, necessary to debate whether the broader uptake of preprints in the humanities is desirable. Counterarguments may be that both the author's initial intention and the reviewer's request for change may be reasonable so that preprint and final publication should reflect such process of change. Moreover, one may argue that attribution of authorship of any publication is entangled already today; that is, reviewers can as well be seen as co-authors-they help with the creation of the work, rather less than more substantially, only that this is opaque today. Preprints will just make visible the difference between manuscript and publication; they will not change that there is a difference. This, however, connects to our understanding of peer review as it is this process, rather than preprints, that makes such co-creation and change opaque today. This directly leads to the next realm that requires attention for open humanities: open peer review.

\subsection{Open Peer Review in the Humanities}

Peer review refers to the practice where fellow scholars evaluate each other's works. The resulting evaluation may be used by editors to provide guidance to authors so that they can improve the manuscript, and to make an informed decision about whether or not to publish. The practice's institutionalisation originates in "debates over grant funding" in the 1970s "and has since been extended to cover a variety of processes by which academics formally evaluate each other's work" [67] (p. 11). However, the process of peer refereeing is much older. It can be traced back to learned societies and their journals in the eighteenth century. It developed as "distinctive editorial practices of learned societies [which] arose from the desire to create forms of collective editorial responsibility for publications which appeared under institutional auspices" [68] (p. 4).

Since then, peer review has been developed into an institutionalised practice, and it is a systemic gatekeeper today. Especially the systemic nature of this practice, captivated by a paradigm of excellence, led to the acceptance of peer review to be a threshold to quality and authenticity, and to the assumption that by merely organising peer review, publishing companies add value to the published material [67]. Some authors argue that peer review is material for scholarship and its quality, as, for instance, Babor et al. do: "[t]he most important criterion for quality and integrity is the peer-review process, as overseen by a qualified journal editor and the journal's editorial board" [69] (p. 51). Gatekeeping is seen as a means of merit and scholarly obligation [70], one that is supposed to be-but often enough does not achieve to be-a democratic process [8]. Finch argues that peer review performs as part of the effectiveness of high-quality channels within the current communication system, in which researchers

4 For a popular example of a preprint as the only—thus final—publication, see [64-66]. 
have "effective and high-quality channels through which they can publish and disseminate their findings, and that they perform to the best standards by subjecting their published findings to rigorous peer review" [25] (p. 17).

Such statements seem ignorant of the limitations of peer review in terms of quality. When refereeing is applied as an entry threshold to communication, it is a sorting mechanism, indeed a procedure of selection that filters content into diffusely constructed classes of quality; but it is not a criterion for quality as such. Moreover, the effectiveness of a practice can be questioned if that practice, on the one hand, withholds research for a longer period in which it is inaccessible to other scholars while, on the other hand, only a selection of one to three fellow scholars is deemed worthy for the judgement about the value of a manuscript in a discourse. It takes, on average, 17 weeks for eventually accepted papers to get through peer review; this period is longer than average in the social sciences and humanities with 22-23 weeks [71]. Many journals in the humanities have "single figure acceptance rates" [8] (p. 168), meaning that a bulk of research is excluded from that discourse to which an author wished to contribute it to. Because of the hidden process, the reasoning behind both ex- and inclusion is opaque to fellow scholars.

It is for these and other reasons that peer review is a contested practice across disciplines. Tennant et al. conclude that "debates surrounding the efficacy and implementation of peer review are becoming increasingly heated, and it is now not uncommon to hear claims that it is "broken" or "dysfunctional"" [72]. Especially for disciplines in the sciences, this practice of gatekeeping and verification judgement is under close scrutiny [73-77]. On the other hand, some authors claim evidence for value in peer review [78] and double-blind procedures in particular [79] for disciplines of the sciences. Others raise concern and enquire the options for opening this practice, claiming increased accountability and transparency [80] or proposing entirely new models such as a preprinting-connected collaborative open peer review [81].

Ross-Hellauer [82] discusses a variety of problems with peer review, most of which affect the realms of quality and credibility fundamentally. He accounts inconsistent and "weak levels of agreement" among referees, questions the authority of their role as gatekeeper, and issues the "'black-box" nature of traditional peer review" as a "[l]ack of accountability and risk[ ... ] of subversion". Most of all, the social component of peer reviewing is set against the "idealized as impartial, objective assessors" based on gender, nationality, institutional affiliation, or language. Backed with (peer reviewed) studies as evidence, Ross-Hellauer's review arrives at a devastating conclusion for this practice. Early experiments such as Peters and Ceci's [83] only add to the impression that modern peer review has long established itself as a contested gatekeeping practice instead of a process of collaborative improvement of research. This criticism questions how peer review really achieves to democratise scholarship, or conform to an objective enterprise-two of Robert Merton's key principles in the sociology of science [84] - resulting in an inevitable debate about making this practice more open and transparent. A concerted and concentrated debate is established within open science, and it is likewise necessary for the humanities, where there are differences in the practice.

Being published in the humanities is much more connected to editorship, where peer reviewers provide the editor with a subjective understanding of the work. Decisions of acceptance or rejection are much more connected to interpretation and argument instead of objectified principles. The name of the editor is highly connected to the value of the journal and the discourse it serves. Editors are "cultural intermediaries who bridge two worlds, insiders-outsiders with a foot in each camp" [10] (p. 45). It is no news, however, that scholars, especially in the humanities, judge and argue in manifold subjective ways [85], making it much harder to compare reviews so as to arrive at a desirable compromise in the process of gatekeeping. Being published with a publishing brand-may it be a journal or a book series-is, thus, more than a question of abstract, objectified quality. Statements of quality are much harder to be made in the humanities than they are in the sciences; it is, here, rather a question of consensus and agreement of reviewers or editors on a particular level of intelligibility. But if 
agreement is not the objective of humanities discourses, why should inclusion in a discourse be based on agreement?

Making the peer review process more open by, for instance, publishing the reviews would not necessarily disturb the mechanism of gatekeeping but make the terms of inclusion more transparent. These terms of inclusion may not be the decisive elements, though; the terms of exclusion are. And the culture of debate may require scholars to know about these terms as well. Moving the position of review from pre- to post-publication would profoundly change the purpose of reviewing from gatekeeping to improving, reconfiguring the emphasis of this practice away from the journal towards the discourse.

Fitzpatrick argues in a similar manner, demanding more progress in the practice and discourse on open peer review $[47,48]$. However, her approach is profoundly shaped by notions of the digital and digital humanities. While she indeed writes about the subjectivity and qualitative representation of humanities scholarship, these arguments are not taken up by a larger discourse outside of digital humanities. The discourse on opening peer review should not be left to either the sciences or digital humanities. It needs to be approached from within the humanities, where connections are drawn to other practices such as preprinting and making statements of value and judgement about scholarship.

\subsection{Liberal Copyright Licences in the Humanities}

Another discussion that stands in line with the elements discussed above concerns the applicability of liberal copyright licences. Licences are fundamental for open scholarship as they are guiding principles for the practice of any form of open publishing as well as the policy work that underpins these practices. Licences are not just crucial for potential readers, indicating how the published material can be accessed and used without consulting author or publisher. They are also responsible for a progressive understanding of authorship where the author is not required to sign over copyright to the publisher. CC BY ${ }^{5}$ is the licence most favoured by open access advocates and organisations (see, for instance, the discussion by Frosio [86] (p. 98); or [87,88]). The reasoning here is that reducing the limitations issued by the creative commons licence (by means of $\mathrm{NC}, \mathrm{ND}, \mathrm{SA})^{6}$ to $\mathrm{BY}$, means limiting the limitation of reuse of the publication simply to attribution of authorship. In other words: "anything less introduces a barrier to the open progress of science" [30] (\$19).

While it is true that CC BY as the "most liberal" licence "imposes no limits on the use and reuse of material so long as the original source is acknowledged" [31]; it is also true that there is a debate whether such liberalism is in favour of discourses in the humanities. A strong position in this matter has Mandler who repeatedly voiced his concern about overtly liberal licences-though supporting open access in general [34]. In an interview he claims that "“reuse" under CC BY authorises practices that we call plagiarism in academic life. I know advocates of CC BY dislike the use of this word, but it is a good word to describe the practice of copying and altering words without specifying how they are altered" [89].

This aligns to what Morrison discusses, criticising that a "poor translation could have a negative impact on a scholar's reputation, whether through the quality of the writing or through other scholars misquoting an inaccurate translation" [90] (p. 54).

This is essentially a problem of the humanities: not only because the humanities live on a variety of languages, thus, making translations a regular necessity; even more so, it is in the humanities where the nuances of argument and expression matter. Both these issues are much less present in disciplines of the sciences. Therefore, the claim made by Morrison and Mandler seems legitimate. In the daily process of discourses, however, I think it is not the licence that is fundamental for this form of misrepresentation. It rather is good or bad scholarly convention, and thus practice, that is responsible.

5 Creative Commons Attribution only licence.

6 Creative Commons Attribution licence with the added restrictions (possible in combinations): NC-NonCommercial; ND-NoDerivatives; SA-ShareAlike. 
Translations are made by other scholars as are discussions and reviews of works cited. The basis of such scholarly practices should be the willingness to not misrepresent a fellow scholar and her argument; if this fails, no amount of altering licences will help maintain scholarly integrity. One may wish to publish only with an ND licence to pre-emptively avoid misrepresentation and still be wrongly represented in discussions and reviews of the published work, or even incorrectly connected to a different argument altogether by means of inattentive referencing. If the integrity of the discourse practices in scholarship are not held high, any pre-emptive steering through licences is futile. If the integrity is in place, however, the steering though licences is not necessary in the first place so that the more liberal licence CC BY may as well be suitable for the humanities.

The suitability of this practice needs to be integrated into a larger discourse that connects it to other elements of open humanities, especially open access and open data (infrastructures), enabling policy workers to draw on it to make informed decisions. Without such integrated discourse, policy workers can draw on only minor, fragmented opinions about this matter, or must resort to open science altogether.

\section{Conclusions}

It seems to be harder for the humanities to speak with a single voice than it is for the sciences. But this must not mean that the humanities need not have a discourse on opening their research and communication practices. The three elements discussed indicate the necessity to have this discourse; the lack of having it in a coherent, focussed manner may harm the progress of scholarship in the humanities in an-arguably inevitable-digital future. Unlike the sciences, where the dialectic between the discourse open science and the advancement of more open science practices results in positive progress, issues in question in the humanities are dispersed into often isolated, disintegrated niche discourses. Especially the close connection of preprinting and open peer review indicates the need to have an integrated, rather than a fragmented discourse. Similar claims for interconnectedness can be made for, for instance, open data and open reproducible research, open evaluation and open metrics and impact, or open access and popular humanities communication. ${ }^{7}$

Another form of interconnectedness concerns book reviews and review articles which may well be called forms of post-publication peer review. In this sense, practices in the humanities include forms of openness already. However, those review publications are at times excluded from debates of open access as, according to principles of open science, primarily original research is to be published open access. Yet, reviewing, and thus debating, scholarship is incremental to discourses in the humanities. To sufficiently debate and find solutions for such an issue, humanities scholars and scholarly communication experts need an integrated discourse that brings these elements of open access and open post-publication peer review together. In its current, disintegrated form, the issues will always run into errors in implementation and be unrelatable to scholars in the traditional humanities disciplines.

Open access alone-likely the most prominent element of open science-is well discussed for publishing practices in the humanities. And there are other practices that, out of the requirement of particular scholarship in the humanities, drive individual, smaller discourses that showcase the need for understanding and advancing practice in this field. Opening access to data of humanities scholarship and building sustainable infrastructures is one such practice. Similar to many other elements in open science that are assumed to be applicable to the humanities, however, it must be understood that " $[\mathrm{t}]$ he concept of research data comes from the sciences, and can only be transferred to the traditional scholarly methods of the humanities to a limited degree" [91]. Though questions of

7 Humanities communication does not exist as a term. This is another curious instance where there is a term called science communication without a comparable counterpart for the humanities. This is the case, either because or although, practices such as publishing in popular media are integral to humanities scholarship (Collini, 2012). It can be argued that there is no need to have such a term because of the integral nature of such publishing practice. The fact that there is no such term and discourse, however, should not lead to the assumption that there is no associated practice. The sciences only seem to be more communicative due to their discourse on and practice of science communication; the humanities conduct this communication integratively. 
publishing data, their infrastructures, and degrees of openness are partly integrated into discourses of the digital humanities $[41,92,93]$, it is not connected paradigmatically to a broader open humanities. But facing a digital future, the humanities need to be open to interdisciplinary knowledge transfer in this realm [94].

This can also be seen in the social sciences, where Herb, for instance, consulted on various elements of open science and their development in sociology, eventually concluding that " $[\mathrm{t}]$ he open knowledge culture is not widespread in sociology" [95] (p. 419; translated by the author) ${ }^{8}$. As stated before, some disciplines and research projects of the social sciences may well be in the realm of the sciences and can, thus, be captured by open science. For those closer to the humanities, this cannot be assumed, especially because their scholarly communication practices are distinct.

Most of all, it can be stated with certainty that the crisis of scholarly communication is not simply one of the sciences. Just because the crisis may have a similar origin, the discipline-specific developments and their potential solutions may not be the same. The origin of this crisis may be seen in the paradigm of false productivity, excellence, and pressure to publish. Due to the differences of practices, this led to dissimilar problems which, for the humanities, are concisely summarised by Rosa:

I am firmly convinced that, at least in the social sciences and the humanities, there is, at present, hardly a common deliberation about the convincing force for better arguments, but rather a non-controllable, mad run rush for more publications, conferences and research-projects the success of which is based on network-structures rather than on argumentational force [96] (p. 55).

More transparency and openness that rid authorship of its stances of formality and reputation may serve as a solution. But the discursive space in which scholars debate the specifics of this solution must not be fragmented and dispersed into niche contributions. There may well be individual contributions to what openness means in the humanities or why it may be beneficial. This is especially true in the digital humanities discourse. But, as discussed above, the digital humanities are focussed on methods much more than on open practices. Yet, scholars in the humanities need a voice to shape their digital, open future. This needs to be a transdisciplinary space, just like digital humanities is one; only that it needs be driven from within the humanities (where digital humanities seems to be driven rather by technology), and dedicated and focussed on the opening of practices (where digital humanities are primarily concerned with methods and projects). This process may start with a disciplinary discourse in individual humanities disciplines, for instance, at conferences or in special issues of dedicated journals. The importance of an open humanities discourse will be to bring these threads together and to serve as a dedicated reference to what open practices means to humanities scholars and what best practices and their problems and implementations are. Open science achieves this for the sciences. There is nothing comparable for the humanities.

Notwithstanding, such a space should not be taken as an openness for granted discourse. As the discussion above shows, not everything that can be opened necessarily works in favour of the knowledge production of its disciplines. It may just as well be the case that the ends of practices instead of the practices themselves are ripe for change so that merely reconfiguring processes may not lead to positive progress. Controversial as this may seem, there needs to be a dedicated discourse on it that brings together the variety of currently disconnected endeavours and proficiencies. Open humanities may serve as a namespace for this.

Funding: The author received funding from the Arts \& Humanities Research Council through the London Arts \& Humanities Partnership.

Conflicts of Interest: The author declares no conflict of interest.

8 Original: 'Die Kultur des offenen Wissens ist in der Soziologie nicht verbreitet.'. 


\section{References}

1. Abbott, A. Chaos of Disciplines; University of Chicago Press: Chicago, IL, USA, 2007.

2. Kagan, J. The Three Cultures. Natural Sciences, Social Sciences, and the Humanities in the 21st Century; Cambridge University Press: Cambridge, UK, 2009.

3. Snow, C.P. The Two Cultures and the Scientific Revolution; Cambridge University Press: Cambridge, UK, 1960.

4. Beiner, M. Humanities. Was Geisteswissenschaft Macht. Und was sie Ausmacht; Berlin University Press: Berlin, Germany, 2009.

5. Bod, R. A New History of the Humanities; Oxford University Press: Oxford, UK, 2013.

6. Daston, L. Objectivity and Impartiality: Epistemic Virtues in the Humanities. In The Making of the Humanities, Volume 2, From Early Modern to Modern Disciplines; Bod, R., Maat, J., Weststeijn, T., Eds.; Amsterdam University Press: Amsterdam, Netherlands, 2012; pp. 27-41.

7. Hamann, J. Die Bildung der Geisteswissenschaften. Zur Genese einer sozialen Konstruktion zwischen Diskurs und Feld; Herbert von Halem Verlag: Köln, Germany, 2014.

8. Hyland, K. Academic Publishing. Issues and Challenges in the Construction of Knowledge; Oxford Applied Linguistics; Oxford University Press: Oxford, UK, 2015.

9. Steiner, F. Dargestellte Autorschaft. Autorkonzept und Autorsubjekt in wissenschaftlichen Texten; Reihe Germanistische Linguistik 282; Niemeyer: Tübingen, Germany, 2009.

10. Thompson, J.B. Books in the Digital Age. The Transformation of Academic and Higher Education Publishing in Britain and the United States; Polity: Cambridge, UK, 2005.

11. Hösle, V. Kritik der verstehenden Vernunft. Eine Grundlegung der Geisteswissenschaften; C.H. Beck: Münich, Germany, 2018.

12. Small, H. The Value of the Humanities; Oxford University Press: Oxford, UK, 2013.

13. Collini, S. What Are Universities for? Penguin: London, UK, 2012.

14. David, P.A. The Historical Origins of 'Open Science': An Essay on Patronage, Reputation and Common Agency Contracting in the Scientific Revolution. Capital. Soc. 2008, 3, 5. [CrossRef]

15. Vicente-Saez, R.; Martinez-Fuentes, C. Open Science now: A Systematic Literature Review for an Integrated Definition. J. Bus. Res. 2018, 88, 428-436. [CrossRef]

16. Madsen, R.R. Scientific Impact and the Quest for Visibility. FEBS J. 2019. [CrossRef] [PubMed]

17. Fecher, B.; Friesike, S. Open Science: One Term, Five Schools of Thought. In Web 2.0 for Scientists and Science 2.0; Springer: Vienna, Austria, 2013; pp. 17-47.

18. Friesike, S.; Widenmayer, B.; Gassmann, O.; Schildhauer, T. Opening Science: Towards an agenda of Open Science in academia and industry. J. Technol. Transf. 2015, 40, 581-601. [CrossRef]

19. Peters, M.A. Openness, Web 2.0 Technology, and Open Science. Policy Futures Educ. 2010, 8, 567-574. [CrossRef]

20. Lahti, L.; da Silva, F.; Laine, M.; Lähteenoja, V.; Tolonen, M. Alchemy \& algorithms: Perspectives on the philosophy and history of open science. RIO 2017, 3. [CrossRef]

21. McKiernan, E.C.; Bourne, P.E.; Brown, C.T.; Buck, S.; Kenall, A.; Lin, J.; McDougall, D.; Nosek, B.A.; Ram, K.; Soderberg, C.K.; et al. How Open Science helps researchers succeed. eLife 2016, 5. [CrossRef] [PubMed]

22. Katz, D.S.; Allen, G.; Barba, L.A.; Berg, D.R.; Bik, H.; Boettiger, C.; Borgman, C.L.; Brown, C.T.; Buck, S.; Burd, R.; et al. The Principles of Tomorrow's University. F1000Research 2018, 7, 1926. [CrossRef]

23. Crane, T. The Philosopher's Tone. The Times Literary Supplement. 2018. Available online: https://www.the-tls. co.uk/articles/public/philosophy-journals-review/ (accessed on 8 October 2019).

24. Brink, C. The Soul of a University. Why Excellence is not enough, 1st ed.; Bristol University Press: Bristol, UK, 2018.

25. Finch, J. Accessibility, Sustainability, Excellence: How to Expand Access to Research Publications. Int. Microbiol. 2013, 16, 125-132. [CrossRef]

26. Eve, M.P. Learned Societies, Open Access and Budgetary Cross-Subsidy. Available online: https://eve.gd/ 2019/09/17/learned-societies-open-access-and-budgetary-cross-subsidy/ (accessed on 27 September 2019).

27. Sperlinger, T.; McLellan, J.; Pettigrew, R. Who Are Universities for? Re-Making Higher Education, 1st ed.; Bristol University Press: Bristol, UK, 2018.

28. Moore, S.; Neylon, C.; Eve, M.P.; O’Donnell, D.P.; Pattinson, D. “Excellence R Us”: University Research and the Fetishisation of Excellence. Palgrave Commun. 2016, 3, 16105. [CrossRef] 
29. Tennant, J.P.; Crane, H.; Crick, T.; Davila, J.; Enkhbayar, A.; Havemann, J.; Kramer, B.; Martin, R.; Masuzzo, P.; Nobes, A.; et al. Hot Topics around Scholarly Publishing. Publications 2019, 7, 34. [CrossRef]

30. Moore, S. A Genealogy of Open Access: Negotiations between Openness and Access to Research. Rev. Fr. Sci. Inf. Commun. 2017. [CrossRef]

31. Crossick, G. Monographs and open access. Insights UKSG J. 2016, 29. [CrossRef]

32. Eve, M.P. Open Access and the Humanities; Cambridge University Press: Cambridge, UK, 2014.

33. Jubb, M. Academic Books and their Futures: A Report to the AHRC and the British Library; AHRC/British Library: London, UK, 2017.

34. Mandler, P. Open Access for the Humanities: Not for Funders, Scientists or Publishers. J. Vic. Cult. 2013, 18, 551-557. [CrossRef]

35. Mandler, P. Open Access: A Perspective from the Humanities. Insights UKSG J. 2014, 27, 166-170. [CrossRef]

36. Berlin Declaration. Available online: https://openaccess.mpg.de/Berlin-Declaration (accessed on 8 October 2019).

37. Kleineberg, M.; Kaden, B. Open Humanities? ExpertInnenmeinungen über Open Access in den Geisteswissenschaften. LIBREAS. Libr. Ideas 2017. Available online: https://libreas.eu/ausgabe32/kleineberg/ (accessed on 8 October 2019).

38. Gardiner, E.; Musto, R.G. The Digital Humanities. A Primer for Students and Scholars; Cambridge University Press: Cambridge, UK, 2015.

39. Gibbs, F.; Owens, T. Building Better Digital Humanities Tools: Toward Broader Audiences and User-Centered Designs. Digit. Humanit. Q. 2012. Available online: http://www.digitalhumanities.org/dhq/vol/6/2/000136/ 000136.html (accessed on 8 October 2019).

40. Bod, R. Who's Afraid of Patterns?: The Particular versus the Universal and the Meaning of Humanities 3.0. BMGN_Low Ctries Hist. Rev. 2013, 128, 171-180. [CrossRef]

41. Borgman, C.L. The Digital Future is Now: A Call to Action for the Humanities. Digit. Humanit. Q. 2010. Available online: http://digitalhumanities.org/dhq/vol/3/4/000077/000077.html (accessed on 8 October 2019).

42. Bianco, J. This Digital Humanities Which Is Not One. In Debates in the Digital Humanities; Gold, M.K., Ed.; University of Minnesota Press: Minneapolis, MS, USA, 2012.

43. Borrelli, A. Wissenschaftsgeschichte zwischen Digitalität und Digitalisierung. Z. Digit. Geisteswiss. 2018. [CrossRef]

44. Pritchard, D. Working Papers, Open Access, and Cyber-infrastructure in Classical Studies. Lit. Linguist. Comput. 2008, 23, 149-162. [CrossRef]

45. Kuhn, A.; Hagenhoff, S. Nicht geeignet oder nur unzureichend gestaltet? Digitale Monographien in den Geisteswissenschaften. Z. Digit. Geisteswiss. 2019. [CrossRef]

46. Fitzpatrick, K. Planned Obsolescence. Publishing, Technology, and the Future of the Academy; New York University Press: New York, NJ, USA, 2011.

47. Fitzpatrick, K. Peer Review, Judgment, and Reading. Profession 2011, 2011, 196-201. [CrossRef]

48. Fitzpatrick, K. Beyond Metrics: Community Authorization and Open Peer Review. In Debates in the Digital Humanities; Gold, M.K., Ed.; University of Minnesota Press: Minneapolis, MS, USA, 2012.

49. Cohen, D.J. The Social Contract of Scholarly Publishing. In Debates in the Digital Humanities; Gold, M.K., Ed.; University of Minnesota Press: Minneapolis, MS, USA, 2012.

50. Foster Open Science Taxonomy. Available online: https://www.fosteropenscience.eu/foster (accessed on 18 September 2019).

51. Neylon, C.; Pattinson, D.; Bilder, G.; Lin, J. On the origin of nonequivalent states: How we can talk about preprints. F1000Research 2017, 6. [CrossRef] [PubMed]

52. Tennant, J.; Bauin, S.; James, S.; Kant, J. The Evolving Preprint Landscape: Introductory Report for the Knowledge Exchange Working Group on Preprints. MetaArXiv 2018. [CrossRef]

53. Crick, T.; Hall, B.; Ishtiaq, S. Reproducibility in Research: Systems, Infrastructure, Culture. J. Open Res. Softw. 2017, 5, 32. [CrossRef]

54. Vale, R.D.; Hyman, A.A. Priority of discovery in the Life Sciences. eLife 2016, 5. [CrossRef] [PubMed]

55. Powell, K. Does it take too long to publish research? Nat. News 2016, 530, 148. [CrossRef]

56. Ginsparg, P. Preprint Déjà Vu. EMBO J. 2016, 35, 2620-2625. [CrossRef]

57. Taubes, G. Electronic Preprints Point the Way to 'Author Empowerment'. Science 1996, 271, 767. [CrossRef] 
58. OSF. Preprint Archive Search on Open Science Framework. Available online: https://osf.io/preprints/discover (accessed on 8 October 2019).

59. Laporte, S. Preprint for the Humanities-Fiction or a real possibility? SocArXiv 2016. [CrossRef]

60. Anonymous. BodoArXiv Preprints: Open Repository for Medieval Studies. Available online: https: //osf.io/preprints/bodoarxiv/ (accessed on 25 May 2019).

61. Geltner, G. Long Live the Curator! Available online: https://www.scienceguide.nl/2018/12/long-live-thecurator/ (accessed on 8 October 2019).

62. Geltner, G. Why Arts \& Humanities Scholars Should Care About Preprints. Available online: http: //www.guygeltner.net/blog/372018why-arts-humanities-scholars-should-care-about-preprints (accessed on 8 October 2019).

63. Delfanti, A. Beams of Particles and Papers: How Digital Preprint Archives Shape Authorship and Credit. Soc. Stud. Sci. 2016, 46, 629-645. [CrossRef]

64. Perelman, G. The entropy formula for the Ricci flow and its geometric applications. arXiv 2002. Available online: https://arxiv.org/abs/math/0211159 (accessed on 8 October 2019).

65. Perelman, G. Ricci flow with surgery on three-manifolds. arXiv 2003. Available online: https://arxiv.org/abs/ math/0303109 (accessed on 8 October 2019).

66. Perelman, G. Finite extinction time for the solutions to the Ricci flow on certain three-manifolds. arXiv 2003. Available online: https://arxiv.org/abs/math/0307245 (accessed on 8 October 2019).

67. Fyfe, A.; Coate, K.; Curry, S.; Lawson, S.; Moxham, N.; Røstvik, C.M. Untangling Academic Publishing: A History of the Relationship between Commercial Interests, Academic Prestige and the Circulation of Research. 2017. Available online: https://zenodo.org/record/546100/files/UntanglingAcPub.pdf (accessed on 8 October 2019).

68. Moxham, N.; Fyfe, A. The Royal Society and the Prehistory of Peer Review, 1665-1965: (accepted manuscript/author version). Hist. J. 2018, 61.

69. Babor, T.F.; Stenius, K.; Pates, R.; Miovský, M.; O’Reilly, J.; Candon, P. Publishing Addiction Science. A Guide for the Perplexed; Ubiquity Press: London, UK, 2017.

70. Caputo, R.K. Peer Review: A Vital Gatekeeping Function and Obligation of Professional Scholarly Practice. Fam. Soc. 2019, 100, 6-16. [CrossRef]

71. Huisman, J.; Smits, J. Duration and Quality of the Peer Review Process: The Author's Perspective. Scientometrics 2017, 113, 633-650. [CrossRef] [PubMed]

72. Tennant, J.P.; Dugan, J.M.; Graziotin, D.; Jacques, D.C.; Waldner, F.; Mietchen, D.; Elkhatib, Y.; Collister, L.B.; Pikas, C.K.; Crick, T.; et al. A Multi-Disciplinary Perspective on emergent and future innovations in Peer Review. F1000Research 2017, 6. [CrossRef]

73. Crane, H.; Ryan, M. In peer review we (don't) trust: How peer review's filtering poses a systemic risk to science. RESEARCHERS. ONE 2018. Available online: https://www.researchers.one/article/2018-09-17 (accessed on 8 October 2019).

74. Ferguson, C.; Marcus, A.; Oransky, I. Publishing: The Peer-Review Scam. Nature 2014, 515, 480-482. [CrossRef] [PubMed]

75. Smith, R. Peer Review: A Flawed Process at the Heart of Science and Journals. J. R. Soc. Med. 2006, 99, 178-182. [CrossRef] [PubMed]

76. Stephan, P.; Veugelers, R.; Wang, J. Reviewers are blinkered by bibliometrics. Nat. News 2017, $544,411$. [CrossRef]

77. Tennant, J.P. The state of the art in peer review. FEMS Microbiol. Lett. 2018, 365. [CrossRef]

78. Siler, K.; Lee, K.; Bero, L. Measuring the effectiveness of scientific gatekeeping. Proc. Natl. Acad. Sci. USA 2015, 112, 360-365. [CrossRef]

79. Tomkins, A.; Zhang, M.; Heavlin, W.D. Reviewer bias in single- versus double-blind peer review. Proc. Natl. Acad. Sci. USA 2017, 114, 12708-12713. [CrossRef]

80. Van Rooyen, S.; Godlee, F.; Evans, S.; Black, N.; Smith, R. Effect of open peer review on quality of reviews and on reviewers' recommendations: A randomised trial. BMJ Clin. Res. Ed. 1999, 318, 23-27. [CrossRef]

81. Perakakis, P.; Taylor, M.; Mazza, M.; Trachana, V. Natural selection of academic papers. Scientometrics 2010, 85, 553-559. [CrossRef]

82. Ross-Hellauer, T. What is Open Peer Review? A Systematic Review. F1000Research 2017, 6. [CrossRef]

83. Peters, D.P.; Ceci, S.J. Peer-review Practices of Psychological Journals: The fate of published articles, submitted again. Behav. Brain Sci. 1982, 5, 187-195. [CrossRef] 
84. Merton, R.K. The Normative Structure of Science. In The Sociology of Science: Theoretical and Empirical Investigations; Merton, R.K., Ed.; University of Chicago Press: Chicago, IL, USA, 1973.

85. Lamont, M. How Professor Think: Inside the Curious World of Academic Judgment; Harvard University Press: Cambridge, MA, USA, 2009.

86. Frosio, G. Open Access Publishing: A Literature Review; Center for Copyright and New Business Models (CREATe): Glasgow, UK, 2014.

87. Neylon, C. Open Access must enable open use. Nature 2012, 492, 348-349. [CrossRef] [PubMed]

88. Suber, P. Strong and Weak OA. Available online: http://legacy.earlham.edu/ \{\}peters/fos/2008/04/strong-andweak-oa.html (accessed on 23 September 2019).

89. Poynder, R. The OA Interviews: Peter Mandler. Available online: https://poynder.blogspot.com/2018/12/theoa-interviews-peter-mandler.html (accessed on 23 September 2019).

90. Morrison, H.G. Freedom for Scholarship in the Internet Age. Available online: http://summit.sfu.ca/item/12537 (accessed on 23 September 2019).

91. Cremer, F.; Klaffki, L.; Steyer, T. Der Chimäre auf der Spur: Forschungsdaten in den Geisteswissenschaften. o-bib. Das offene Bibliotheksjournal 2018, 5, 142-162.

92. Brehm, E.; Neumann, J. Anforderungen an Open-Access-Publikation von Forschungsdaten-Empfehlungen für einen offenen Umgang mit Forschungsdaten. o-bib. Das offene Bibliotheksjournal 2018, 5, 1-16.

93. Lemaire, M. Vereinbarkeit von Forschungsprozess und Datenmanagement in den Geisteswissenschaften. o-bib. Das offene Bibliotheksjournal 2018, 5, 237-247.

94. Arnold, T.; Tilton, L. New Data? The Role of Statistics in DH. In Debates in the Digital Humanities, 2019; Gold, M.K., Klein, L.F., Eds.; University of Minnesota Press: Minneapolis, MS, USA, 2019.

95. Herb, U. Open Science in der Soziologie. Eine interdisziplinäre Bestandsaufnahme zur offenen Wissenschaft und eine Untersuchung ihrer Verbreitung in der Soziologie; Schriften zur Informationswissenschaft 67; Hülsbusch: Glückstadt, Germany, 2015.

96. Rosa, H. Alienation and Acceleration. Towards a Critical Theory of Late-Modern Temporality; NSU Press: Malmö, Sweden, 2010.

(C) 2019 by the author. Licensee MDPI, Basel, Switzerland. This article is an open access article distributed under the terms and conditions of the Creative Commons Attribution (CC BY) license (http://creativecommons.org/licenses/by/4.0/). 